CARVALHO, L.A.; TESSARIOLI NETO, J. Produtividade de tomate em ambiente protegido, em função do espaçamento e número de ramos por planta. Horticultura Brasileira, Brasília, v.23, n.4, p.986-989, out-dez 2005.

\title{
Produtividade de tomate em ambiente protegido, em função do espaçamento e número de ramos por planta ${ }^{1}$
}

\author{
Léa A. de Carvalho ${ }^{1}$; João Tessarioli Neto ${ }^{2}$ \\ ${ }^{1}$ Centro de Ciências Agrárias e Ambientais, UFBA, 44380.000 Cruz das Almas-BA; E-mail:lacarval@ufba.br; ${ }^{2}$ ESALQ/USP, Depto. de \\ Produção Vegetal, C. Postal 09, 13418-900 Piracicaba-SP (in memoriam)
}

\section{RESUMO}

Avaliou-se o efeito do espaçamento e do número de ramos por planta na produção de híbridos de tomate, cultivados em substrato, sob ambiente protegido. O experimento foi conduzido de março a outubro. Utilizou-se o delineamento em blocos casualizados, em esquema fatorial 4X2X2, sendo quatro híbridos (Andréa, Débora Max, Carmen e Diana), dois espaçamentos entre plantas (0,30 e 0,45 $\mathrm{m}$ ) e duas conduções (um e dois ramos por planta), com quatro repetições. Foram determinados o número de frutos comercializáveis (frutos planta $\left.{ }^{-1}\right)$, produção total comercializável $\left(\mathrm{t} \mathrm{ha}^{-1}\right)$, massa média do fruto comercializável ( $\mathrm{g}$ fruto), produção de frutos grande, médios e pequenos $\left(\mathrm{t} \mathrm{ha}^{-1}\right)$. Os resultados mostraram que o manejo mais indicado foi o espaçamento de $0,30 \mathrm{~m}$ entre plantas conduzidas com uma haste, sendo que o híbrido 'Débora Max' apresentou o maior potencial produtivo.

Palavras-chave: Lycopersicon esculentum Mill., rendimento, condução, densidade populacional.

\begin{abstract}
Yield of tomato under protected environment in relation to spacing and number of branches per plant

The effects of plant spacing and number of branches per plant were investigated in the production of tomatoes when different hybrids were grown in a substratum under protected environment. The work was conducted from March to October. High tomato yield under protected environment depends on the proper management. The experiment followed a randomized blocks design, in a factorial arrangement of $4 \times 2 \times 2$, with four hybrids (Andréa, Debora Max, Carmen and Diana), two spacings between plants $(0.30$ and $0.45 \mathrm{~m})$ and two conduction systems ( 1 and 2 branches per plant). The treatments were replicated four times. The following parameters were studied: marketable yield (fruits plant ${ }^{-1}$ ), total marketable yield ( $\mathrm{ha}^{-1}$ ), average weight of marketable fruit ( $\mathrm{g}$ ) and yield of big, medium, and small fruits $\left(\mathrm{t} \mathrm{ha}^{-1}\right)$. According to the results the spacing of 0.30 $\mathrm{m}$ between plants and one branch per plant were the best combinations with the hybrid 'Debora Max' showing the highest potential yield.
\end{abstract}

Keywords: Lycopersicon esculentum Mill., yield, conduction, plant density.

\section{(Recebido para publicação em 4 de outubro de 2004 e aceito em 31 de agosto de 2005)}

$\mathrm{O}$ cultivo em ambiente protegido de tomate tem se expandido nos últimos anos, principalmente, nas regiões Sul e Sudeste do Brasil e esta técnica propicia ao tomateiro um incremento na produção, podendo ser de 4 a 15 vezes superiores àquelas obtidas em campo (MARTINS, 1992). O uso intensivo do solo com uma espécie e a sua salinização em ambiente protegido, vem gradativamente sinalizando para o cultivo sem solo, especialmente em sacos plásticos, contendo substrato apropriado. Este sistema permite um manejo mais adequado tanto da água como de nutrientes. Segundo Andriolo et al. (1997), as plantas cultivadas em substrato proporcionalmente fixam mais matéria seca nos frutos, sendo, portanto mais eficientes em termos de rendimento, obtendo-se inclusive a mesma pro- dução com menor área foliar, o que possibilita a utilização de maior densidade de plantas, com melhor arejamento e menor risco de moléstias.

A elevada produtividade obtida em plantios adensados ocorre devido ao aumento da interceptação da luz fotossinteticamente ativa e da fotossíntese no dossel, que estimula o crescimento da cultura e aumenta o total de assimilados disponíveis para os frutos ( P A P A D O P O U L O S ; PARARAJASINGHAM, 1997). No tomateiro, além do adensamento, o número de plantas por unidade de área, o número de frutos colhidos por plantas e a massa média dos frutos estão diretamente relacionados à produtividade ( P A P A D O P O U L O S ; PARARAJASINGHAM, 1997; STRECK et al., 1998). Apesar de ocorrer um aumento na produção do tomateiro com o adensamento de plantas, a massa média do fruto decresce (STRECK et al., 1996; PAPADOPOULOS; PARARAJASINGHAM, 1997; CAMARGOS, 1998; STRECK et al. 1998; CAMARGOS et al., 2000), e depende da época do ano (MARTINS, 1992; STRECK et al., 1996) e do híbrido utilizado (SCHMIDT et al., 2000; LOGENDRA et al., 2001).

A produção e a massa média de tomate comercial, também são influenciadas pela densidade de plantas e pelo número de ramos por planta. Quanto maior o adensamento e o número de ramos por planta menor será a produção total comercial, a produção de frutos grandes e a massa média dos frutos grande e médio, e maior será a produção de frutos médio e pequeno (OLIVEIRA et

${ }^{1}$ Parte da tese de doutorado do primeiro autor 
al., 1995; CAMARGOS, 1998). Já Seleguini et al. (2002) verificaram que apenas na produção de frutos médios houve um aumento linear da produtividade com o aumento da densidade. Este efeito da densidade de plantas na produção e massa média de tomate classificado ocorre porque em condições de adensamento as plantas competem mais por luz e direcionam um maior gasto de energia aos processos de crescimento celular e menor translocação de açúcares para os frutos, resultando numa diminuição do diâmetro do fruto (BORRAZ et al., 1991).

Além da exigência do mercado consumidor quanto à massa média dos frutos para o consumo in natura, que segundo Martins (1992) e Fayad et al. (2001) é do tipo grande para o tipo Santa Cruz e do tipo médio para o tipo Salada. Campos et al. (1987) e Oliveira (1993) reportaram que existe uma correlação positiva entre o maior tamanho do fruto e a ocorrência de rachadura, $o$ que torna o fruto muito grande não comerciável. Diante do exposto, o presente trabalho teve por objetivo avaliar a produção comercial total e em diversas classes, de quatro híbridos de tomate, quando submetidos a dois espaçamentos e conduzidos com um ou dois ramos, no cultivo em ambiente protegido e substrato.

\section{MATERIAL E MÉTODOS}

$\mathrm{O}$ experimento foi conduzido em ambiente protegido de março a outubro, em área experimental da ESALQ, em Piracicaba (SP). A casa de vegetação seguiu o modelo arco, com área de 196 $\mathrm{m}^{2}(7 \times 28)$, coberta com plástico transparente de $150 \mu$ e as partes frontais e laterais com telado tipo clarite. Os híbridos Andréa, Débora Max, Carmen e Diana, foram semeados em 08/03/2001, em bandejas de poliestireno expandido contendo 128 células e preenchida com o substrato Plantmax. Adubou-se semanalmente com $1 \mathrm{~g} \mathrm{~L}^{-1}$ de Plant Prod 2020-20. Após 28 dias as mudas, apresentando $4-5$ folhas definitivas foram transplantadas.

O delineamento experimental foi em blocos ao acaso, com quatro repetições, em um esquema fatorial $4 \times 2 \times 2$, onde $o$

Tabela 1. Cronograma de fertirrigação com Kristalon do tomateiro estaqueado. Piracicaba, ESALQ, 2002.

\begin{tabular}{|c|c|c|c|}
\hline Período (dias) & Estádio da planta & Kristalon (N-P-K) & Dose $\left(\mathrm{g} \mathrm{L}^{-1}\right)$ \\
\hline $1-15$ & Estabelecimento & Amarelo (13-40-13) & 0,3 \\
\hline \multirow[t]{3}{*}{$16-45$} & Crescimento & Branco (15-5-30) & $0,5-0,7$ \\
\hline & & Nitrato de Cálcio & 0,3 \\
\hline & & Nitrato de Magnésio líquido & 0,2 \\
\hline \multirow[t]{3}{*}{$46-75$} & Até a 1ª Floração & Laranja (6-12-36) & $0,3-0,5$ \\
\hline & & Nitrato de Cálcio & $0,6-0,8$ \\
\hline & & Nitrato de Magnésio líquido & 0,2 \\
\hline \multirow[t]{2}{*}{ 76-Final } & Produção & Laranja (6-12-36) & $0,9-1,1$ \\
\hline & & Nitrato de Cálcio & $0,2-0,4$ \\
\hline
\end{tabular}

primeiro fator foi constituído por quatro híbridos (Andréa, Carmen, Débora Max e Diana), o segundo pelo número de ramos (um e dois) e o terceiro por dois espaçamentos $(0,30$ e $0,45 \mathrm{~cm}$ entre plantas). Cada parcela experimental foi composta por oito e doze plantas, de acordo com o espaçamento, dispostas em fileira dupla numa área de 3,06 m², sendo que todas as plantas foram consideradas úteis. A condução foi feita em fileiras duplas, sendo as plantas distribuídas sobre canteiros distanciados de $1,10 \mathrm{~m}$ entre si. $\mathrm{O}$ espaçamento entre as duas linhas dentro do canteiro foi de $0,60 \mathrm{~m}$ e entre as plantas nas linhas de 0,30 e $0,45 \mathrm{~m}$. O cultivo foi realizado em sacos contendo $15 \mathrm{~L}$ de substrato comercial (Rendmax Estufa), na densidade de duas e três plantas por saco. $\mathrm{Na}$ casa de vegetação os sacos foram colocados sobre os canteiros que foram revestidos com filme de polietileno preto de baixa densidade.

O sistema de irrigação utilizado foi, o de gotejamento e as fertirrigações diárias foram feitas com Kristalon, segundo as recomendações da Hydro Fertilizantes para a cultura do tomate (Tabela 1). A poda apical foi feita acima da terceira folha emitida após o sexto e quinto rácimos da haste principal e secundária, respectivamente. Em todos os híbridos, o desbaste dos frutos foi feito deixando-se quatro frutos por rácimo ao longo das hastes e nos racimos das extremidades apenas três.

O controle fitossanitário foi curativo, à medida que apareciam os primeiros sintomas das doenças e pragas, segundo as recomendações para a cultura do tomate descritas por Lopes e Santos (1994). Para o controle da larva minadora (Liriomyza sp.), broca pequena (Neuleucinodes elegantalis) e traça (Tuta absoluta e/ou Phthorimaea operculella), aplicou-se semanalmente Decis 25. Para o controle das doenças fúngicas, aplicou-se Oxicloreto de cobre e o Benomil, em intervalos de quinze dias. Aos 100 dias após o transplante (DAT), ocorreu o aparecimento de sintomas típicos de oídio (Erysiphe cichoracearum), isto é, pó branco e fino na superfície de cima e de baixo das folhas mais velhas (FILGUEIRA, 2000; LOPES; SANTOS,1994).

Os frutos foram colhidos a partir do momento em que apresentaram o ápice com coloração avermelhada até totalmente vermelhos, porém firmes. As colheitas foram realizadas a intervalos médios de cinco dias, no período de 19/ 06 a 02/10, dependendo dos tratamentos. As plantas conduzidas com um ramo e espaçadas a 0,30 e 0,45 m tiveram o ciclo de 167 e 158 dias, respectivamente, enquanto que as plantas com dois ramos, independente do espaçamento, tiveram o ciclo de 180 dias.

Os frutos foram classificados segundo o diâmetro transversal, em: oblongos; grandes (>60 mm); médios $(<60 \mathrm{~mm}$ e $>50 \mathrm{~mm})$ e pequenos $(<50$ mm e >40); redondo-achatados; Para Carmen e Diana foram classificados em: grande (>80 mm); médio (<80 $\mathrm{mm} \mathrm{e}$ $>65 \mathrm{~mm})$ e pequeno $(<65 \mathrm{~mm}$ e $>50$ $\mathrm{mm}$ ) e miúdos ( $>50 \mathrm{~mm})$. Frutos com defeitos não foram considerados comercializáveis (CEAGESP, 1998). Como não existe recomendação para os frutos do híbrido Andréa (tipo Italiano), os mesmos foram classificados, devido ao seu formato, como frutos oblongos (tipo Santa Cruz). 
Tabela 2. Características do produto comercial de quatro híbridos de tomate cultivado em túnel de polietileno e substrato, em função do espaçamento e número de ramos por planta. Piracicaba, ESALQ, 2002.

\begin{tabular}{|c|c|c|c|c|c|}
\hline \multirow{2}{*}{ Híbridos } & \multicolumn{2}{|c|}{ Espaçamento (m) } & \multicolumn{2}{|c|}{$N^{\circ}$ de Ramos } & \multirow{2}{*}{ Média } \\
\hline & 0,30 & 0,45 & 1 & 2 & \\
\hline \multicolumn{2}{|c|}{$\mathrm{N}^{\circ}$ de frutos (frutos.planta-1) } & \multicolumn{2}{|c|}{$\mathrm{CV}(\%) 10,33$} & & \\
\hline Andréa & $22,08 \mathrm{Ba}$ & $22,36 \mathrm{Ba}$ & $16,39 \mathrm{Bb}$ & $28,06 \mathrm{Ba}$ & $22,22 \mathrm{C}$ \\
\hline Débora Max & $28,01 \mathrm{Aa}$ & $28,61 \mathrm{Aa}$ & $21,12 \mathrm{Ab}$ & $35,50 \mathrm{Aa}$ & $28,31 \mathrm{~A}$ \\
\hline Carmen & $25,00 \mathrm{ABa}$ & $26,46 \mathrm{Aa}$ & $20,33 \mathrm{ABb}$ & $31,13 \mathrm{Ba}$ & $25,73 \mathrm{~B}$ \\
\hline Diana & $24,38 \mathrm{ABa}$ & $26,67 \mathrm{Aa}$ & $19,88 \mathrm{ABb}$ & $31,17 \mathrm{Ba}$ & $25,53 \mathrm{~B}$ \\
\hline Média & 24,87 a & $26,03 \mathrm{a}$ & $14,43 \mathrm{~b}$ & 31,47 a & \\
\hline \multicolumn{2}{|c|}{ Produtividade (t ha-1) } & \multicolumn{2}{|c|}{ C.V. (\%) 14,08} & & \\
\hline Andréa & $65,11 \mathrm{Ba}$ & $47,10 \mathrm{Bb}$ & $44,51 \mathrm{Cb}$ & $67,70 \mathrm{Ba}$ & $56,10 \mathrm{C}$ \\
\hline Débora Max & $98,78 \mathrm{Aa}$ & $65,06 \mathrm{Bb}$ & $71,73 \mathrm{Bb}$ & $95,15 \mathrm{Aa}$ & $81,94 \mathrm{~B}$ \\
\hline Carmen & $115,03 \mathrm{Aa}$ & $89,52 \mathrm{Ab}$ & $97,78 \mathrm{Aa}$ & $106,77 \mathrm{Aa}$ & $102,28 \mathrm{~A}$ \\
\hline Diana & $110,63 \mathrm{Aa}$ & $89,36 \mathrm{Ab}$ & $89,85 \mathrm{ABb}$ & $110,15 \mathrm{Aa}$ & $100,00 \mathrm{~A}$ \\
\hline Média & 97,39 a & $72,77 \mathrm{~b}$ & $75,96 \mathrm{~b}$ & 94,19 a & \\
\hline \multicolumn{2}{|c|}{ Massa média (g.fruto) } & \multicolumn{2}{|c|}{ C.V. (\%) 6,51} & & \\
\hline Andréa & $75,92 \mathrm{Ca}$ & $81,17 \mathrm{Ba}$ & $83,52 \mathrm{Ca}$ & $73,57 \mathrm{Bb}$ & $78,55 \mathrm{C}$ \\
\hline Débora Max & $92,64 \mathrm{Ba}$ & $89,05 \mathrm{Ba}$ & $101,68 \mathrm{Ba}$ & $80,00 \mathrm{Bb}$ & $90,84 \mathrm{~B}$ \\
\hline Carmen & $120,78 \mathrm{Ab}$ & $134,27 \mathrm{Aa}$ & $149,24 \mathrm{Aa}$ & $105,81 \mathrm{Ab}$ & $127,52 \mathrm{~A}$ \\
\hline Diana & $118,20 \mathrm{Ab}$ & $132,37 \mathrm{Aa}$ & $140,61 \mathrm{Aa}$ & $109,96 \mathrm{Ab}$ & $125,29 \mathrm{~A}$ \\
\hline Média & $101,88 \mathrm{~b}$ & $109,22 \mathrm{a}$ & 118,76 a & $92,33 \mathrm{~b}$ & \\
\hline
\end{tabular}

Médias seguidas pela mesma letra maiúscula na coluna e minúscula na linha, para cada característica, não diferem entre si pelo teste de Tukey (5\% P).

Tabela 3. Produtividade classificada $\left(\mathrm{t} \mathrm{ha}^{-1}\right)$ do tomateiro cultivado em túnel de polietileno e substrato, em função de híbrido, espaçamento e número de ramos por planta. Piracicaba, ESALQ, 2002.

\begin{tabular}{|c|c|c|c|c|c|}
\hline \multirow{2}{*}{ Híbridos } & \multicolumn{2}{|c|}{ Espaçamento (m) } & \multicolumn{2}{|c|}{$N^{\circ}$ de Ramos } & \multirow{2}{*}{ Média } \\
\hline & 0,30 & 0,45 & 1 & 2 & \\
\hline Grande & \multicolumn{4}{|c|}{ C.V.(\%) 69,83} & \\
\hline Andréa & $0,00 \mathrm{Ba}$ & $1,02 \mathrm{Ba}$ & $1,02 \mathrm{Ba}$ & $0,00 \mathrm{Ba}$ & $0,51 \mathrm{~B}$ \\
\hline Débora Max & $28,47 \mathrm{Aa}$ & $14,38 \mathrm{Ab}$ & $30,31 \mathrm{Aa}$ & $12,55 \mathrm{Ab}$ & $24,43 \mathrm{~A}$ \\
\hline Carmen & $1,77 \mathrm{Ba}$ & $5,98 \mathrm{Ba}$ & $7,75 \mathrm{Ba}$ & $0,00 \mathrm{Bb}$ & $3,88 \mathrm{~B}$ \\
\hline Diana & $0,75 \mathrm{Ba}$ & $2,27 \mathrm{Ba}$ & $2,54 \mathrm{Ba}$ & $0,48 \mathrm{Ba}$ & $1,51 \mathrm{~B}$ \\
\hline Média & $7,75 \mathrm{a}$ & $5,91 \mathrm{a}$ & $10,40 \mathrm{a}$ & $3,26 \mathrm{~b}$ & \\
\hline Médio & \multicolumn{4}{|c|}{ C.V. (\%) 28,00} & \\
\hline Andréa & $20,44 \mathrm{Ba}$ & $20,86 \mathrm{Ba}$ & $21,92 \mathrm{Ba}$ & $19,38 \mathrm{Ca}$ & $20,65 \mathrm{~B}$ \\
\hline Débora Max & $54,63 \mathrm{Aa}$ & $39,12 \mathrm{Ab}$ & $36,23 \mathrm{Bb}$ & $57,54 \mathrm{Aa}$ & $46,88 \mathrm{~A}$ \\
\hline Carmen & $58,17 \mathrm{Aa}$ & $50,72 \mathrm{Aa}$ & $69,63 \mathrm{Aa}$ & $39,26 \mathrm{ABb}$ & $54,45 \mathrm{~A}$ \\
\hline Diana & $43,27 \mathrm{Ba}$ & 49,79 $\mathrm{Aa}$ & $58,01 \mathrm{Aa}$ & $35,05 \mathrm{Bb}$ & $46,53 \mathrm{~A}$ \\
\hline Média & 44,13 a & 40,12 a & $46,45 \mathrm{a}$ & $37,81 \mathrm{~b}$ & \\
\hline Pequeno & \multicolumn{4}{|c|}{ C.V. $(\%) 14,02$} & \\
\hline Andréa & $44,67 \mathrm{Ca}$ & $25,22 \mathrm{Bb}$ & $21,57 \mathrm{ABb}$ & $48,32 \mathrm{Ba}$ & $34,95 \mathrm{C}$ \\
\hline Débora Max & $15,65 \mathrm{Da}$ & $11,60 \mathrm{Ca}$ & $5,19 \mathrm{Cb}$ & $22,06 \mathrm{Ca}$ & $13,63 \mathrm{D}$ \\
\hline Carmen & $55,08 \mathrm{Ba}$ & $32,83 \mathrm{ABb}$ & $20,39 \mathrm{Bb}$ & $67,52 \mathrm{Aa}$ & $43,95 \mathrm{~B}$ \\
\hline Diana & $66,61 \mathrm{Aa}$ & $37,31 \mathrm{Ab}$ & $29,30 \mathrm{Ab}$ & $74,62 \mathrm{Aa}$ & $51,96 \mathrm{~A}$ \\
\hline Média & $45,51 \mathrm{a}$ & $26,74 \mathrm{~b}$ & $19,11 b$ & $53,13 a$ & \\
\hline
\end{tabular}

Médias seguidas pela mesma letra maiúscula na coluna e minúscula na linha para cada classe, não diferem entre si pelo teste de Tukey (5\% P).

Avaliou-se o número de frutos comercializável (frutos planta-1), produção total comercializável $\left(\mathrm{t} \mathrm{ha}{ }^{-1}\right)$, massa média de fruto comercializável ( $\mathrm{g}$ fruto), produção de frutos grande, médios e pequenos $\left(\mathrm{t} \mathrm{ha}^{-1}\right)$.
Os efeitos e interações foram avaliados pelo teste F. Havendo diferença significativa para um determinado fator estudado, as médias dos tratamentos foram comparadas pelo teste de Tukey, ao nível de 5\% de probabilidade.

\section{RESULTADOS E DISCUSSÃO}

A análise de variância para os híbridos estudados mostrou não haver interação entre o espaçamento e o número de ramos por planta para número de frutos por planta, produção e massa média comercial. $\mathrm{O}$ espaçamento não afetou o número de frutos e devido ao aumento na produção de biomassa ocasionado pelo maior número de plantas por área, maiores produções $\left(97,39 \mathrm{t} \mathrm{ha}^{-1}\right)$ foram obtidas na maior densidade (Tabela 2). Com a ocorrência da maior produção de biomassa é provável que a interceptação de luz fotossinteticamente ativa e da fotossíntese no dossel tenha aumentado a produção $\mathrm{de}$ fotoassimilados que foram disponibilizados para os frutos ( P A P A D O P O U L O S ; PARARAJASINGHAM, 1997). Os resultados do presente trabalho concordam com os obtidos por vários autores (STRECK et al., 1996; $\mathrm{P}$ A P A D O P O U L O S ; PARARAJASINGHAM, 1997; STRECK et al. 1998; CAMARGOS, 1998; CAMARGOS et al., 2000). O peso médio do fruto foi grandemente influenciado pelo híbrido utilizado. As cultivares híbridas Carmen e Diana apresentaram maior massa média comercial na menor densidade e 'Andréa' e 'Débora Max' não foram afetados, provavelmente, devido à melhor arquitetura da planta que proporcionou uma menor competição interplanta pela luz e intraplanta pelos fotoassimilados ( P A P A D O P O U L O S ; PARARAJASINGHAM, 1997).

O numero de ramos por planta afetou o número de frutos por planta, a massa média e a produção comercial. Independentemente dos híbridos as plantas conduzidas com dois ramos apresentaram maior número de frutos por planta e a menor massa média comercial de frutos (Tabela 2). Com exceção de 'Carmen' que não diferiu quanto 
à produção comercial os demais híbridos diferiram e apresentaram valores médios superiores nas plantas conduzidas com dois ramos. $\mathrm{O}$ aumento no número de frutos e na produção comercial e a redução na massa média das plantas com dois ramos foram devido ao maior número de inflorescências produtivas e à maior competição entre inflorescências pelos fotoassimilados, respectivamente. Tais resultados foram também relatados por Oliveira (1993) e Oliveira et al. (1995) em campo e Poerschke et al. (1995) em estufa de polietileno.

Houve interação entre híbridos, espaçamento e número de ramos por planta para a produção de fruto grande (Tabela 3). O híbrido 'Débora Max' apresentou maior produção de fruto grande nas plantas conduzidas com um ramo e espaçadas a $0,30 \mathrm{~m}$ e 'Carmen', apesar de não ter diferido de 'Andréa' e 'Diana' apresentou maiores produções nas plantas com um ramo. Quanto à produção de fruto médio, a cultivar Débora Max apresentou maior produção na maior densidade e nas plantas conduzidas com dois ramos, porém não diferiu significativamente de 'Carmen' e 'Diana'. Apesar dos híbridos do tipo salada não apresentarem diferenças com relação ao espaçamento, a cultivar Carmen apresentou maior produção de frutos médios quando o espaçamento adotado foi de $30 \mathrm{~cm}$. O aumento da produção de frutos médios com a diminuição do espaçamento entre plantas observado no híbrido Débora Max já foi observado em outros híbridos por vários autores (CAMARGOS, 1998; STRECK et al. 1998; CAMARGOS et al., 2000). O número de ramos por planta não afetou a produção de frutos médios de 'Andréa'. 'Carmen' e 'Diana', que apresentaram valores médios superiores nas plantas conduzidas com um ramo, provavelmente devido a menor competição intraplanta pelos fotoassimilados.

À exceção do espaçamento para 'Débora Max', maior produção de fruto pequeno foi obtida na maior densidade e nas plantas conduzidas com dois ramos (Tabela 3). Esse efeito pode ter sido ocasionado pelo maior gasto de energia em processos de crescimento celular pela planta e menor translocação de açúcares para os frutos, resultando num menor diâmetro do fruto, conforme citação de Borraz et al. (1991).

$\mathrm{Na}$ maior densidade e nas plantas conduzidas com um ramo os híbridos do tipo Salada diferiram ente si, sendo que o híbrido 'Diana' apresentou maior produção de fruto pequeno. A menor produção de frutos pequenos na maior densidade e nas plantas conduzidas com dois ramos no híbrido 'Carmen', confirma a sua superioridade em relação ao Diana.

Nas condições que em que foi realizado o experimento, conclui-se que o espaçamento entre plantas de $0,30 \mathrm{~m} \mathrm{e}$ a condução com uma haste é o mais indicado para o cultivo do tomate em ambiente protegido e em substrato; sendo o híbrido 'Débora Max' o que apresentou o maior potencial produtivo.

\section{AGRADECIMENTOS}

Ao Prof. Dr. João Tessarioli Neto (In memoriam), pela orientação e amizade. Á EUCATEX, pela doação do Rendmax-Estufa e a TOOPSEED, pela doação das sementes.

\section{LITERATURA CITADA}

ANDRIOLO, J.L.; DUARTE, T.S.; LUDKE, L.; SKREBSKY, E.C. Crescimento e desenvolvimento do tomateiro cultivado em substrato com fertirrigação. Horticultura Brasileira, Brasília, v.15, n.1, p.28-32, 1997

BORRAZ, C.J.; CASTILHO, S.F.; ROBELES, E.P. Efectos del despunte y la densidad de poblacion sobre dos variedades de jitomate (Lycopersicon esculentum, Mill), en hidroponía bajo invernadero. Chapingo, v.14, n.73/74, p.26-30, 1991

CAMARGOS, M.I. Produção e qualidade de tomate longa vida em estufa, em função do espaçamento e do número de cachos por planta. Viçosa: UFV, 1998. 68 f. Dissertação (Mestrado) - Universidade Federal de Viçosa, Viçosa. CAMARGOS, M.I.; FONTES, P.C.R.; CARDOSO, A.A.; CARNICELLI, J.H.A. Produção de tomate longa vida em estufa, influenciada por espaçamento e número de cachos por planta. Horticultura Brasileira, Brasília v.18, p.563-564, jul., 2000. Suplemento. CAMPOS, J.P.; BRLFORT, C.C.; GALVÃO, J.D.; FONTES, P.C.R. Efeito da poda de haste e da população de plantas sobre a produção do tomateiro. Revista Ceres, v.34, n.191, p.198-208, 1987. CEAGESP. Classificação do tomate. São Paulo: CQH/CEAGESP. 1998. 8 p. (folder).
FAYAD, J.A.; FONTES, P.C.R.; CARDOSO, A.A.; FINGER, F.L.; FERREIRA, F.A. Crescimento e produção do tomateiro cultivado sob condições de campo e de ambiente protegido. Horticultura Brasileira, Brasília, v.19, n.3, p.365370, 2001.

FILGUEIRA, F.A.R. Novo manual de olericultura: agrotecnologia moderna na produção e comercialização de hortaliças. Viçosa: UFV, 2000. 402 p.

LOGENDRA, L.S.; GIANFAGNA, T.J.; SPECCA, D.R.; JANES, H.W. Greenhouse tomato limited cluster production systems: Crop management practices affect yield. HortScience, v.36, n.5, p.893-896. 2001.

LOPES, C.A.; SANTOS, J.R.M. Doenças do tomateiro. Brasília: EMBRAPA, SPI, 1994. 67p. LOPES, C.A.; SANTOS, J.R.M. dos. Doenças do tomateiro. Brasília: EMBRAPA, SPI, 1994. 67 p. MARTINS, G. Uso de casa de vegetação com cobertura plástica na tomaticultura de verão. 1992. 65 f. Tese (Doutorado) - Faculdade de Ciências Agrárias e Veterinárias, Universidade Estadual Paulista "Júlio de Mesquita Filho", Jaboticabal. OLIVEIRA, V.R. Número de ramos por planta, poda apical e época de plantio influenciando a produção e a qualidade dos frutos de tomateiro (Lycopersicon esculentum Mill.). 1993. 114 f. Tese (Doutorado) Universidade Federal de Viçosa, Viçosa.

OLIVEIRA, V.R.; CAMPOS, J.P.; FONTES, P.C.R.; REIS, F.P. Efeito do numero de hastes por planta e poda apical na produção classificada de frutos de tomateiro (Lycopersicon esculentum Mill.). Ciência e Prática, v.19, n.4, p.414-419, 1995. ORTOLANI, A.A.; CAMARGO, M.B.P. Influência dos fatores climáticos na produção. In: CASTRO P.R.C.; FERREIRA, S.; YAMADA, T. (Ed.). Ecofisiologia da produção agrícola. Piracicaba: ABPPF, 1987. p.71-81.

PAPADOPOULOS, A.P.; PARARAJASINGHAM, $S$. The influence of plant spacing on light interception and use in greenhouse tomato (Lycopersicon esculentum Mill.): Areview. Scientia Horticulturae, v.69, p.1-29, 1997.

POERSCHKE, P.R.C.; BURIOL, G. A.; STRECK, N.A.; ESTEFANEL, V. Efeito de sistemas de poda sobre o rendimento do tomateiro cultivado em estufa de polietileno. Ciência Rural, Santa Maria, v.25, n.3, p.379-384, 1995.

SCHMIDT, D.; SANTOS, O.S.; BONNECARRÈRE, A.G.; PILAU, F.G. Potencial produtivo de tomate cultivado com alta densidade em hidroponia. Horticultura Brasileira, Brasília, v.18, p.273-274, jul., 2000. Suplemento. SELEGUINI, A.; SENO, S.; ZIZAS, G.B. Influência do espaçamento entre plantas e número de cachos por plantas na cultura do tomateiro, em condições de ambiente protegido. Horticultura Brasileira, Brasília, v.20, n.2, Jul., p. 25-28, 2002. Suplemento.

STRECK, N.A.; BURIOL, G.A.; SCHNEIDER, F.M. Efeito da densidade de plantas sobre a produtividade do tomateiro cultivado em estufa de plástico. Pesquisa Agropecuária Brasileira, Brasília, v.31, n.2, p.105-112, 1996.

STERCK, N.A.; BURIOL, G.A.; ANDRIOLO, J.L.; SANDRI, M.A. Influência da densidade de plantas e da poda apical drástica na produtividade do tomateiro em estufa de plástico. Pesquisa Agropecuária Brasileira, Brasília v.33, n.7. p.1105-1112, jul.1998. 